\title{
A Methodology Based on Rough Set Theory and Hypergraph for the Prediction of Wart Treatment
}

\author{
Hossam A. Nabwey ${ }^{1,2}$, Abdulfattah Omar ${ }^{3}$ \\ ${ }^{1}$ Department of Mathematics, College of Science and Humanities in Al-Kharj, Prince Sattam bin Abdulaziz University, Al-Kharj11942, Saudi Arabia. \\ ${ }^{2}$ Department of Basic Engineering Science, Faculty of Engineering, Menoufia University, Shebin El-Kom, 32511, Egypt. \\ ${ }^{3}$ Department of English, College of Science and Humanities in Al-Kharj, Prince Sattam bin Abdulaziz University, Al-Kharj11942, Saudi Arabia.
}

${ }^{3}$ https://orcid.org/0000-0002-7167-3822

\begin{abstract}
Retrieving meaningful information from high dimensional dataset is an important and challenging task. Normally, medical dataset suffers from several issues such as curse of dimensionality problem, massive generation of highdimensional medical datasets from various biomedical applications, uncertainty, presence of missing values, nonrelevant and redundant attributes, etc. All of these issues harden the data analytic process for precise medical diagnosis. This work proposes an efficient feature selection methodology for finding the optimal feature subset which can be devised as a prominent solution to the above-said challenge. The proposed methodology based on rough set theory and hypergraph to identify the optimal feature subset for accurate prediction of wart treatment. In this work we use dataset contains information about wart treatment results of 90 patients using immunotherapy. A rough set with Boolean reasoning discretization algorithm is introduced to discretize the data, then the rough set reduction technique is applied to find all reducts. After that the principles of hypergraph was applied to determine the minimal transversal of reducts. Finally, a set of generalized rules for wart treatment was extracted. The proposed model shows a higher efficiency in terms of reduct size, time complexity and overall accuracy rates as well as generates more compact rules.
\end{abstract}

Keywords: classification of medical data ; medical diagnosis; Wart Treatment; Hypergraph; Rough set theory; feature selection, Immunotherapy.

\section{1) INTRODUCTION}

The advancement of technologies and enrichment in data collection methods have increased the size of the data which led to an enormous information load. The size of real time dataset is increasing day by day in both dimensions (along rows and columns) and also there is high chance of having missing of information. One of the crucial problems with these high dimensional datasets is that all the (column) attributes may not be equally significant for different knowledge discovery or data mining applications [1].

Machine learning and data mining algorithms are utilized to analyze large datasets and discover and extract knowledge from them. They are also employed as a tool in medical sciences [2-4], crime detection, risk assessment, and sales of products. These algorithms can analyze data in order to discover the unknown patterns in large databases. Industries such as banking, insurance, health, and marketing commonly apply them in order to reduce costs, improve the quality of research, and increase the amount of sales.

Attribute (feature) selection [5] is one of the important techniques of dimensionality reduction process to handle the high dimensionality issue. Attribute selection is used to select a subset of relevant attributes from a large attribute space that preserves the semantics of the original content without destroying the underlying meaning of the attributes. In the last few years, significant number of attribute selection methods is proposed by various researchers [6-8] which works in different ways by using arrange of evaluation measures like probability distribution, entropy, correlation, etc. Besides these methods rough set theory (RST) $[9,10]$ is one of the successful approximation based mathematical model to deal the imprecision and uncertainty present in knowledge. Indiscernibility relation of RST is the backbone concept to select minimal representative attribute subset from a dataset. In this regard four main advantages of RST in data analysis may be highlighted as, first, it is based only on the original data and does not require any external input or information; secondly, it assists in identifying and selecting the most information-rich attributes from a dataset and has the capability to return it as a minimal attribute subset; finally, in terms of computational effort, it is highly efficient, as it is based on simple set operations and it can strictly deals with indiscernibility, imprecision and uncertainty. Many heuristic algorithms are proposed based on rough set theory, also numerous approached based on rough set theory and other 
theories are investigated to extract decision rules and reduce the dimensionality of dataset [11-23]. One advantage of the rough set is the creation of readable if-then rules. Such rules have a potential to reveal new patterns in the data material. Thus, the ultimate goal of this work is to present a Methodology based on rough set theory and hypergraph for accurate prediction of wart treatment.

\section{2)}

\section{HYPERGRAPH}

Over the past few decades, graphical representations were widely used by many researchers for the model binary relationships among the objects. A graph is represented as an ordered pair $=\{V, E\}$, where $\mathrm{V}$ and $\mathrm{E}$ correspond to the vertices and edges, respectively. In a real world scenario, where there exists n-ary relationship among the objects, ordinary graphical representations fail to uncover this kind of relation among the objects. In such cases, hypergraph has proven its efficiency in both defining and describing the n-ary relationships among the objects [24 - 26]. This section discusses basic definitions of the hypergraph and few exciting properties such as vertex linearity and minimal transversal which can be hybridized with RST to identify the optimal feature subset.

According to [27] consider $U$ be a finite set of non-empty elements. If $E=\left(\left(E_{i}\right)_{i \in j} \neq\{\}\right)$ and $\bigcup E_{i}=V, i \in j$ then $H=(V, E)$ is an hypergraph as shown in fig. 1, where $V=\left\{v_{1}, v_{2}, v_{3}, \ldots ..\right\}$ and $E=\left\{e_{1}, e_{2}, e_{3}, \ldots ..\right\}$ represent the vertices and edges, respectively. Hyperedges of $\mathrm{H}$ are represented

$e_{i}=\left\{e_{i 1}, e_{i 2}, e_{i 3}, \ldots . . e_{i j}\right\}(i \in j ; j=1,2,3, \ldots . . n)$

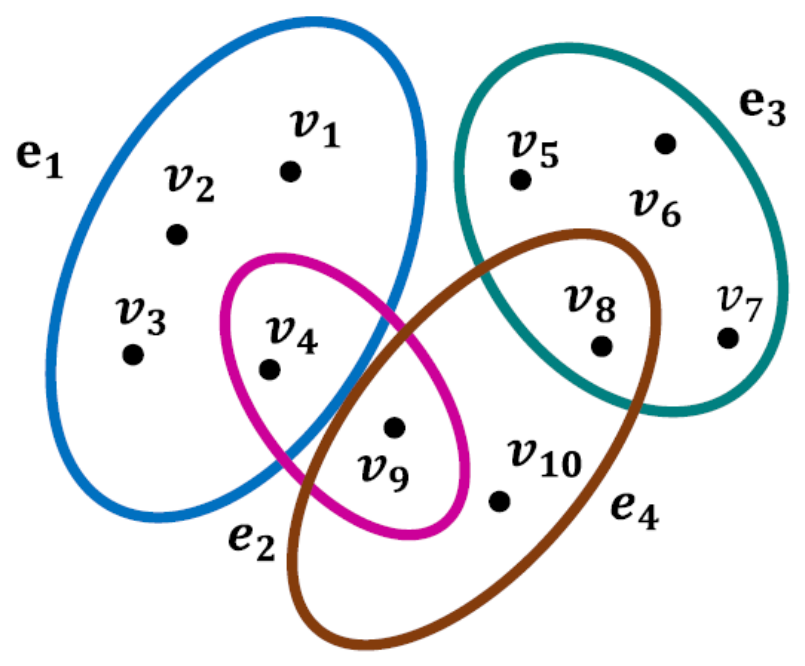

Fig. 1: Hypergraph structure
According to [28] $H=(V, E)$ for $k \in V$, then set of hyperedges that contain $\mathrm{k}$ is known as star of $\mathrm{H}$ which is represented as $H(k)$ and degree of $\mathrm{k}$ is the cardinality of star $H(k)$ denoted as $k_{d}=\operatorname{Card}(H(k))$. From Fig.1 $V=\left\{v_{1}, v_{2}, v_{3}, v_{4}, v_{5}, v_{6}, v_{7}, v_{8}, v_{9}, v_{10}\right\}$; set of hyperedges $e_{1}=\left\{v_{1}, v_{2}, v_{3}, v_{4}\right\}, e_{2}=\left\{v_{4}, v_{9}\right\}$, $e_{3}=\left\{v_{5}, v_{6}, v_{7}, v_{8}\right\}, e_{4}=\left\{v_{8}, v_{9}, v_{10}\right\} ;$ the star centered on $v_{8}$ is $H\left(k_{8}\right)=\left\{e_{3}, e_{4}\right\}$ and $k_{8 d}=2$; the star centered on $v_{4}$ is $H\left(k_{4}\right)=\left\{e_{1}, e_{2}\right\}$ and $k_{4 d}=2$.

According to [28, 29]:

a) $H=(V, E)$ be a simple (Sperner family) only for every $E_{a}, E_{b} \in E$; if $E_{a} \not \subset E_{b}$, it implies $a \neq b$. The set of $H \subseteq V$ is known as transversal of $H$ only when it intersects every hyperedge of $H$.

b) The transversal hypergraph $T_{H}^{r}$ of hypergraph $\mathrm{H}$ is a set of all minimal transversals of $H$.

\section{PROBLEM FORMULATION}

In medical research, one of the most important fields is skin disease, and among the skin diseases wart treatment. Warts are non-cancerous (benign) skin growths that develop on different parts of the body and come in various forms. They are caused by caused by the human papillomavirus (HPV) viruses. Warts are contagious and very common: Most people will have one at some point in their lives. Although they can affect people at any age, warts are most common among children and teenagers. Most warts are harmless and will go away on their own within a few weeks or months. But they can be bothersome and unattractive, and some people feel ashamed. There are a number of different treatments that can make warts go away more quickly - but they don't always work. Most warts don't cause any bothersome symptoms. Some may cause itching, tightness or a feeling of pressure. Warts might be painful too, particularly those on the soles of your feet. Some warts have small black or brownish dots caused by clotted blood that has leaked from capillaries (very fine blood vessels) in the skin. Warts may appear alone or in groups, which may then cover larger areas of skin. The main types of warts are shown in Fig. 2. There are two methods for treatment, cryotherapy method and immunotherapy method. A number of medical studies have been done to compare these two treatment methods. 


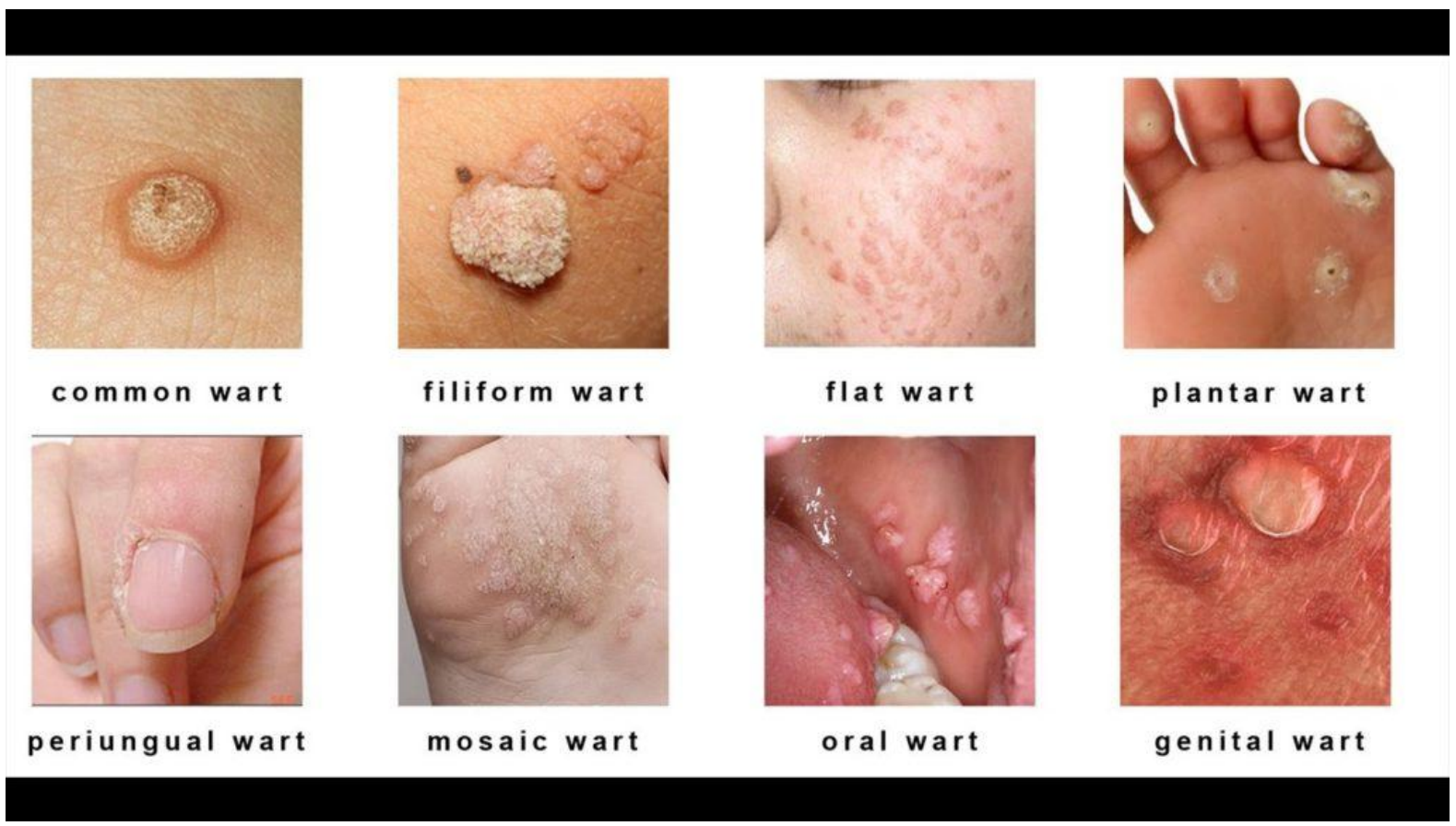

Fig. 2: Types of Warts

The main goal of this work is to present Methodology based on rough set theory and hypergraph for generating classification to predict the response of wart treatment. The data set is taken from the UCI machine learning repository $[30,31]$. This dataset contains information about wart treatment results of 90 patients using immunotherapy. We consider the Response to treatment as the decision variable. The attributes that play major wart treatment are presented in the decision table shown in Table 2, where to write it in a simple form and to make our analysis simple we used the coding shown in table 1.

Table 1.Coding system for the Symptoms and decision attribute

\begin{tabular}{|l|c|c|}
\hline attribute & Attribute code & Attribute value \\
\hline Gender & A & 1-Man \\
\hline Age (year) & B & $15-56$ \\
\hline Time elapsed before treatment (month) & C & $0-12$ \\
\hline The number of warts & E & $1-19$ \\
\hline Surface area of the warts(mm2) & F & 6-900 \\
\hline Induration diameter of initial test(mm) & G & 5-70 \\
\hline Types of wart & H & 2- Plantar \\
& & 3- Both \\
\hline Response to treatment & & Yes or No \\
\hline
\end{tabular}


Table 2. Decision table for wart treatment

\begin{tabular}{|c|c|c|c|c|c|c|c|c|}
\hline $\mathbf{U}$ & $\mathbf{A}$ & B & C & $\mathbf{E}$ & $\mathbf{F}$ & $\mathbf{G}$ & $\mathbf{H}$ & D \\
\hline X1 & 1 & 22 & 2.25 & 14 & 3 & 51 & 50 & 1 \\
\hline $\mathrm{X} 2$ & 1 & 15 & 3 & 2 & 3 & 900 & 70 & 1 \\
\hline $\mathbf{X 3}$ & 1 & 16 & 10.5 & 2 & 1 & 100 & 25 & 1 \\
\hline X4 & 1 & 27 & 4.5 & 9 & 3 & 80 & 30 & 1 \\
\hline X5 & 1 & 20 & 8 & 6 & 1 & 45 & 8 & 1 \\
\hline X6 & 1 & 15 & 5 & 3 & 3 & 84 & 7 & 1 \\
\hline $\mathbf{X} 7$ & 1 & 35 & 9.75 & 2 & 2 & 8 & 6 & 1 \\
\hline X8 & 2 & 28 & 7.5 & 4 & 1 & 9 & 2 & 1 \\
\hline X9 & 2 & 19 & 6 & 2 & 1 & 225 & 8 & 1 \\
\hline $\mathbf{X 1 0}$ & 2 & 32 & 12 & 6 & 3 & 35 & 5 & 0 \\
\hline X11 & 2 & 33 & 6.25 & 2 & 1 & 30 & 3 & 1 \\
\hline $\mathrm{X} 12$ & 2 & 17 & 5.75 & 12 & 3 & 25 & 7 & 1 \\
\hline X13 & 2 & 15 & 1.75 & 1 & 2 & 49 & 7 & 0 \\
\hline X14 & 2 & 15 & 5.5 & 12 & 1 & 48 & 7 & 1 \\
\hline X15 & 2 & 16 & 10 & 7 & 1 & 143 & 6 & 1 \\
\hline X16 & 2 & 33 & 9.25 & 2 & 2 & 150 & 8 & 1 \\
\hline X17 & 2 & 26 & 7.75 & 6 & 2 & 6 & 5 & 1 \\
\hline X18 & 2 & 23 & 7.5 & 10 & 2 & 43 & 3 & 1 \\
\hline X19 & 2 & 15 & 6.5 & 19 & 1 & 56 & 7 & 1 \\
\hline $\mathbf{X} 20$ & 2 & 26 & 6.75 & 2 & 1 & 6 & 6 & 1 \\
\hline X21 & 1 & 22 & 1.25 & 3 & 3 & 47 & 3 & 1 \\
\hline $\mathrm{X} 22$ & 2 & 19 & 2.25 & 2 & 1 & 60 & 7 & 1 \\
\hline X23 & 2 & 26 & 10.5 & 6 & 1 & 50 & 9 & 0 \\
\hline X24 & 1 & 25 & 5.75 & 2 & 1 & 300 & 7 & 1 \\
\hline $\mathrm{X} 25$ & 2 & 17 & 11.25 & 4 & 3 & 70 & 7 & 1 \\
\hline X26 & 1 & 27 & 5 & 2 & 1 & 20 & 5 & 1 \\
\hline X27 & 2 & 24 & 4.75 & 10 & 3 & 30 & 45 & 1 \\
\hline X28 & 1 & 15 & 11 & 6 & 1 & 30 & 25 & 0 \\
\hline X29 & 2 & 34 & 11.5 & 12 & 1 & 25 & 50 & 0 \\
\hline X30 & 2 & 20 & 7.75 & 18 & 3 & 45 & 2 & 1 \\
\hline X31 & 2 & 38 & 2.5 & 1 & 3 & 43 & 50 & 1 \\
\hline X32 & 1 & 23 & 3 & 2 & 3 & 87 & 70 & 1 \\
\hline X33 & 2 & 48 & 10.25 & 7 & 1 & 50 & 25 & 1 \\
\hline X34 & 2 & 24 & 4.25 & 1 & 1 & 174 & 30 & 1 \\
\hline X35 & 2 & 33 & 8 & 3 & 1 & 502 & 8 & 1 \\
\hline X36 & 1 & 34 & 5 & 7 & 3 & 64 & 7 & 0 \\
\hline X37 & 2 & 41 & 11 & 11 & 2 & 21 & 6 & 0 \\
\hline X38 & 1 & 29 & 8.75 & 3 & 1 & 504 & 2 & 1 \\
\hline X39 & 2 & 22 & 8.5 & 5 & 1 & 99 & 8 & 1 \\
\hline
\end{tabular}


International Journal of Engineering Research and Technology. ISSN 0974-3154 Vol.13, No.3 (2020), pp. 552-559 (C) International Research Publication House. https://dx.doi.org/10.37624/IJERT/13.3.2020.552-559

\begin{tabular}{|c|c|c|c|c|c|c|c|c|}
\hline X40 & 1 & 45 & 11.25 & 4 & 1 & 72 & 5 & 0 \\
\hline X41 & 2 & 22 & 8.25 & 9 & 1 & 352 & 3 & 1 \\
\hline X42 & 1 & 35 & 8.75 & 10 & 2 & 69 & 7 & 1 \\
\hline X43 & 2 & 34 & 8.5 & 1 & 2 & 163 & 7 & 0 \\
\hline X44 & 1 & 49 & 4.5 & 2 & 1 & 33 & 7 & 0 \\
\hline $\mathrm{X} 45$ & 2 & 19 & 11 & 5 & 2 & 51 & 6 & 1 \\
\hline $\mathrm{X} 46$ & 1 & 21 & 8 & 3 & 1 & 17 & 8 & 1 \\
\hline X47 & 1 & 26 & 7.75 & 13 & 2 & 13 & 5 & 1 \\
\hline X48 & 1 & 51 & 8.75 & 2 & 2 & 57 & 3 & 1 \\
\hline X49 & 1 & 19 & 7.75 & 6 & 1 & 32 & 7 & 1 \\
\hline X50 & 1 & 38 & 12 & 14 & 1 & 87 & 6 & 0 \\
\hline X51 & 2 & 36 & 1.75 & 10 & 3 & 45 & 3 & 1 \\
\hline X52 & 2 & 52 & 2.25 & 5 & 1 & 63 & 7 & 1 \\
\hline X53 & 2 & 49 & 9 & 4 & 2 & 14 & 9 & 1 \\
\hline X54 & 1 & 23 & 5.75 & 2 & 1 & 43 & 7 & 1 \\
\hline X55 & 1 & 45 & 10 & 8 & 1 & 58 & 7 & 1 \\
\hline X56 & 1 & 54 & 7.5 & 13 & 3 & 43 & 5 & 1 \\
\hline $\mathbf{X 5 7}$ & 2 & 47 & 5.25 & 3 & 3 & 23 & 45 & 1 \\
\hline $\mathbf{X 5 8}$ & 2 & 53 & 10 & 1 & 2 & 30 & 25 & 1 \\
\hline X59 & 2 & 56 & 11.75 & 7 & 1 & 31 & 50 & 0 \\
\hline $\mathbf{X 6 0}$ & 1 & 27 & 11.25 & 3 & 2 & 37 & 2 & 1 \\
\hline X61 & 2 & 47 & 3.75 & 14 & 2 & 67 & 50 & 1 \\
\hline X62 & 2 & 19 & 2.25 & 8 & 2 & 42 & 70 & 1 \\
\hline X63 & 2 & 33 & 8 & 5 & 1 & 63 & 25 & 1 \\
\hline X64 & 2 & 15 & 4 & 12 & 1 & 72 & 30 & 1 \\
\hline X65 & 1 & 17 & 8.5 & 2 & 1 & 44 & 8 & 1 \\
\hline X66 & 1 & 29 & 5 & 12 & 3 & 75 & 7 & 1 \\
\hline X67 & 1 & 27 & 11.75 & 8 & 1 & 208 & 6 & 0 \\
\hline X68 & 2 & 51 & 6 & 6 & 1 & 80 & 2 & 1 \\
\hline X69 & 1 & 35 & 6.75 & 4 & 3 & 41 & 8 & 1 \\
\hline X70 & 2 & 47 & 10.75 & 8 & 1 & 57 & 5 & 0 \\
\hline X71 & 1 & 43 & 8 & 1 & 1 & 59 & 3 & 1 \\
\hline X72 & 1 & 15 & 4 & 4 & 3 & 25 & 7 & 1 \\
\hline X73 & 1 & 33 & 1.75 & 7 & 2 & 379 & 7 & 0 \\
\hline X74 & 2 & 51 & 4 & 1 & 1 & 65 & 7 & 1 \\
\hline X75 & 1 & 45 & 6.5 & 9 & 2 & 49 & 6 & 1 \\
\hline X76 & 2 & 47 & 9.25 & 13 & 2 & 367 & 8 & 1 \\
\hline X77 & 1 & 18 & 11.75 & 5 & 2 & 13 & 5 & 1 \\
\hline X78 & 2 & 46 & 7.75 & 8 & 1 & 40 & 3 & 1 \\
\hline X79 & 1 & 43 & 11 & 7 & 1 & 507 & 7 & 1 \\
\hline X80 & 2 & 28 & 11 & 3 & 3 & 91 & 6 & 0 \\
\hline
\end{tabular}


International Journal of Engineering Research and Technology. ISSN 0974-3154 Vol.13, No.3 (2020), pp. 552-559

(C) International Research Publication House. https://dx.doi.org/10.37624/IJERT/13.3.2020.552-559

\begin{tabular}{||l|c|c|c|c|c|c|c|c||}
\hline $\mathbf{X 8 1}$ & 1 & 30 & 1 & 2 & 1 & 88 & 3 & 1 \\
\hline $\mathbf{X 8 2}$ & 2 & 16 & 2 & 11 & 1 & 47 & 7 & 1 \\
\hline $\mathbf{X 8 3}$ & 2 & 42 & 8.75 & 8 & 2 & 73 & 9 & 0 \\
\hline $\mathbf{X 8 4}$ & 2 & 15 & 8 & 1 & 1 & 55 & 7 & 1 \\
\hline $\mathbf{X 8 5}$ & 2 & 53 & 7.25 & 6 & 1 & 81 & 7 & 1 \\
\hline $\mathbf{X 5 6}$ & 1 & 40 & 5.5 & 8 & 3 & 69 & 5 & 1 \\
\hline $\mathbf{X 8 7}$ & 1 & 38 & 7.5 & 8 & 2 & 56 & 45 & 1 \\
\hline $\mathbf{X 8 8}$ & 1 & 46 & 11.5 & 4 & 1 & 91 & 25 & 0 \\
\hline $\mathbf{X 8 9}$ & 1 & 32 & 12 & 9 & 1 & 43 & 50 & 0 \\
\hline $\mathbf{X 9 0}$ & 2 & 23 & 6.75 & 6 & 1 & 19 & 2 & 1 \\
\hline \hline
\end{tabular}

\section{4) ANALYSIS}

In this section, we will discuss the proposed rough sets and hypergraph scheme to analyze, mining and generating classification rules for predict the response of wart treatment. The main stages will be done with the aid of software called ROSETTA which is an RST analysis toolkit. First, rough sets with Boolean reasoning discretization algorithm is introduced to discretize the data, second step, the rough set reduction technique is applied to find all reducts of the data which contains the minimal subset of attributes that are associated with a class label for classification as shown in table 3 .

Table 3. Reducts of Table 2.

\begin{tabular}{||l|l|c|c||}
\hline & Reduct & Support & Length \\
\hline 1 & $\{A, B, C, E, G\}$ & 100 & 5 \\
\hline 2 & $\{A, B, C, E, F\}$ & 100 & 5 \\
\hline 3 & $\{A, B, C, E, H\}$ & 100 & 5 \\
\hline 4 & $\{A, B, C, F, G, H\}$ & 100 & 6 \\
\hline
\end{tabular}

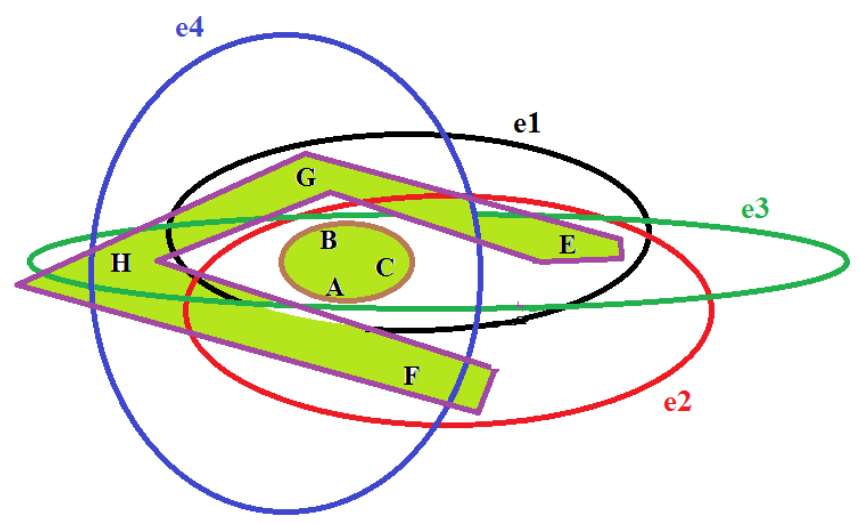

Fig. 3: Hypergraph with minimal transversal property
The next stage is applying the hypergraph principles to determine the minimal transversal of reducts. Consider the hypergraph $H=(V, E) \quad$ where $V=\{A, B, C, E, F, G, H\}, E=\left\{e_{1}, e_{2}, e_{3}, e_{4}\right\}$; set of hyperedges $e_{1}=\{A, B, C, E, G\} e_{2}=\{A, B, C, E, F\}$, $e_{3}=\{A, B, C, E, H\}, \quad e_{4}=\{A, B, C, F, G, H\}$; the minimal transversal of $\mathrm{H}$ hypergraph is $\{\{A, B, C\},\{E, F, G, H\}\}$ as shown in Fig. 3. Finally, the rough sets dependency rules are generated directly as shown in table 4.

\section{CONCLUSION}

This paper introduced a methodology for predicting the response of wart treatment based on rough set theory and hypergraph. The proposed methodology hybridizes the benefits of RST and Sperner hypergraph properties. The minimal transversal properties of hypergraph were exploited on the reducts obtained from RST to identify the informative feature subset for health-care applications. The proposed technique has been simplified logic-based rules required to building knowledge. Also it was observed that this system can greatly and effectively reduce both the time and cost of treatment for patients. an extension work of using rough sets with other intelligent systems like neural networks, genetic algorithms, fuzzy approaches, and so forth, will be considered in the future work.

\section{ACKNOWLEDGMENTS}

The author thank Prince Sattam bin Abdulaziz University, Deanship of Scientific Research at Prince Sattam bin Abdulaziz University for their continuous support and encouragement. 
International Journal of Engineering Research and Technology. ISSN 0974-3154 Vol.13, No.3 (2020), pp. 552-559

(C) International Research Publication House. https://dx.doi.org/10.37624/IJERT/13.3.2020.552-559

Table 4. The generated rules to predict the response of wart treatment

\begin{tabular}{|c|c|c|c|c|c|c|}
\hline & Rule & LHS Support & RHS Support & RHS Accuracy & LHS Coverage & RHS Coverage \\
\hline 1 & 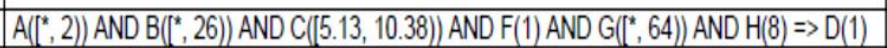 & 3 & 3 & 1.0 & 0.033333 & 0.042254 \\
\hline 2 & $\mathrm{~A}\left(\left(2,{ }^{*}\right)\right)$ AND B([", 26)) AND C((5.13, 10.38)) AND F(1) AND G([",64)) AND H(7) $\Rightarrow$ D(1) & 3 & 3 & 1.0 & 0.033333 & 0.042254 \\
\hline 3 & 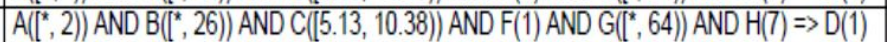 & 2 & 2 & 1.0 & 0.022222 & 0.028169 \\
\hline 4 & $\mathrm{~A}\left(\left[{ }^{*}, 2\right)\right)$ AND B $\left(\left[{ }^{*}, 26\right)\right)$ AND C $\left(\left[\left[^{*}, 5.13\right)\right)\right.$ AND F(3) AND $G\left(\left(64,{ }^{*}\right)\right)$ AND $H(70) \Rightarrow D(1)$ & 2 & 2 & 1.0 & 0.022222 & 0.028169 \\
\hline 5 & 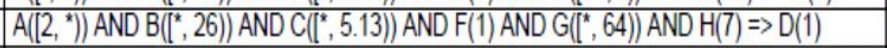 & 2 & 2 & 1.0 & 0.022222 & 0.028169 \\
\hline 6 & $\mathrm{~A}\left(\left(2,{ }^{*}\right)\right)$ AND B $\left(\left[{ }^{*}, 26\right)\right)$ AND C $([5.13,10.38))$ AND F(1) AND $G\left(\left(64,{ }^{*}\right)\right)$ AND H(8) $\Rightarrow$ D $(1)$ & 2 & 2 & 1.0 & 0.022222 & 0.028169 \\
\hline 7 & $\mathrm{~A}\left(\left[2,{ }^{*}\right)\right)$ AND B $\left(\left[{ }^{*}, 26\right)\right)$ AND C $\left(\left[{ }^{*}, 5.13\right)\right)$ AND $F(1)$ AND $G\left(\left(64,{ }^{*}\right)\right)$ AND $H(30) \Rightarrow D(1)$ & 2 & 2 & 1.0 & 0.022222 & 0.028169 \\
\hline 8 & 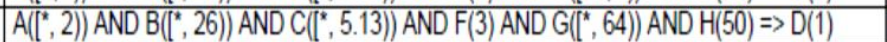 & 1 & 1 & 1.0 & 0.011111 & 0.014085 \\
\hline 9 & $\mathrm{~A}\left(\left[{ }^{*}, 2\right)\right)$ AND B( $\left.\left({ }^{*}, 26\right)\right)$ AND C((10.38, $\left.\left.{ }^{*}\right)\right)$ AND F(1)AND G((64, $\left.\left.{ }^{*}\right)\right)$ AND H(25) $\Rightarrow$ D(1) & 1 & 1 & 1.0 & 0.011111 & 0.014085 \\
\hline 10 & $\mathrm{~A}\left(\left[{ }^{*}, 2\right)\right)$ AND B((26,31)) AND C( $\left.\left({ }^{*}, 5.13\right)\right)$ AND F(3) AND $G\left(\left(64,{ }^{*}\right)\right)$ AND H(30) $\Rightarrow$ D $(1)$ & 1 & 1 & 1.0 & 0.011111 & 0.014085 \\
\hline 11 & 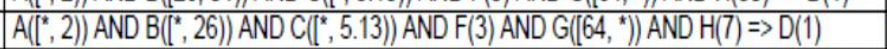 & 1 & 1 & 1.0 & 0.011111 & 0.014085 \\
\hline 12 & $\left.\mathrm{~A}\left({ }^{*}, 2\right)\right)$ AND B $((31,43))$ AND C $([5.13,10.38))$ AND F(2) AND G( $\left.\left({ }^{*}, 64\right)\right)$ AND $H(6) \Rightarrow$ D(1 & 1 & $\mid 1$ & 1.0 & 0.011111 & 0.014085 \\
\hline 13 & $\mathrm{~A}\left(\left(2,{ }^{*}\right)\right)$ AND B $((26,31))$ AND C((5.13, 10.38)) AND F(1) AND G(" $\left.\left.{ }^{*}, 64\right)\right)$ AND H(2) $\Rightarrow$ D(1 & 1 & 1 & 1.0 & 0.011111 & 0.014085 \\
\hline 14 & $\mathrm{~A}\left(\left(2,{ }^{*}\right)\right)$ AND B((31, 43)) AND C((10.38, $\left.\left.{ }^{*}\right)\right)$ AND F(3) AND G( $\left.\left({ }^{*}, 64\right)\right)$ AND $H(5) \Rightarrow D(0)$ & 1 & 1 & 1.0 & 0.011111 & 0.052632 \\
\hline 15 & $\mathrm{~A}\left(\left(2,{ }^{*}\right)\right) \mathrm{AND} B((31,43))$ AND $\mathrm{C}((5.13,10.38))$ AND $F(1)$ AND G( $\left.\left({ }^{2}, 64\right)\right)$ AND $\mathrm{H}(3) \Rightarrow \mathrm{D}(1$ & 1 & 1 & 1.0 & 0.011111 & 0.014085 \\
\hline 16 & $\mathrm{~A}\left(\left(2,{ }^{*}\right)\right)$ AND B $\left.\left({ }^{*}, 26\right)\right)$ AND $C((5.13,10.38))$ AND F(3) AND G( $\left.\left({ }^{*}, 64\right)\right)$ AND H(7) $\Rightarrow$ D(1) & 1 & 1 & 1.0 & 0.011111 & 0.014085 \\
\hline 17 & A((2, $\left.\left.{ }^{*}\right)\right)$ AND B( $\left.\left({ }^{*}, 26\right)\right)$ AND C( $\left.\left({ }^{*}, 5.13\right)\right)$ AND F(2)AND G([*, 64)) AND H(7) $\Rightarrow$ D(0) & 1 & 1 & 1.0 & 0.011111 & 0.052632 \\
\hline 18 & $\mathrm{~A}\left(\left(2,{ }^{*}\right)\right)$ AND B( $\left.\left({ }^{*}, 26\right)\right)$ AND C( $\left.(5.13,10.38)\right)$ AND F(1) AND $G\left(\left(64,{ }^{*}\right)\right)$ AND $H(6) \Rightarrow D(1)$ & 1 & 1 & 1.0 & 0.011111 & 0.014085 \\
\hline 19 & $\mathrm{~A}\left(\left(2,{ }^{*}\right)\right) \operatorname{AND~B}((31,43)) \operatorname{AND} \mathrm{C}((5.13,10.38)) \operatorname{AND} \mathrm{F}(2)$ AND G($\left.\left(64,{ }^{*}\right)\right) \operatorname{AND~H}(8) \Rightarrow \mathrm{D}(1$ & 1 & 1 & 1.0 & 0.011111 & 0.014085 \\
\hline 20 & 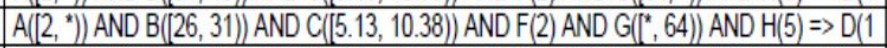 & 1 & 1 & 1.0 & 0.011111 & 0.014085 \\
\hline 21 & $\left.\mathrm{~A}\left(\left(2,{ }^{*}\right)\right) \operatorname{AND~B}\left({ }^{*}, 26\right)\right)$ AND $C((5.13,10.38))$ AND F(2) AND G( $\left.\left({ }^{*}, 64\right)\right)$ AND H(3) $\Rightarrow \mathrm{D}(1)$ & 1 & 1 & 1.0 & 0.011111 & 0.014085 \\
\hline 22 & $\mathrm{~A}\left(\left(2,{ }^{*}\right)\right) \operatorname{AND~B}((26,31)) \operatorname{AND} \mathrm{C}((5.13,10.38)) \operatorname{AND} \mathrm{F}(1)$ AND G( $\left.\left({ }^{*}, 64\right)\right) \operatorname{AND} \mathrm{H}(6) \Rightarrow \mathrm{D}(1$ & 1 & 1 & 1.0 & 0.011111 & 0.014085 \\
\hline 23 & 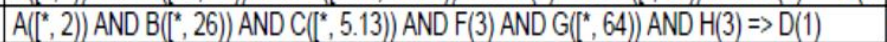 & 1 & 1 & 1.0 & 0.011111 & 0.014085 \\
\hline 24 & $\mathrm{~A}\left(\left(2,{ }^{*}\right)\right) \operatorname{AND} \mathrm{B}((26,31))$ AND C((10.38, $\left.\left.{ }^{*}\right)\right)$ AND F(1) AND G($\left.\left({ }^{*}, 64\right)\right)$ AND H(9) $\Rightarrow \mathrm{D}(0)$ & 1 & 1 & 1.0 & 0.011111 & 0.052632 \\
\hline 25 & 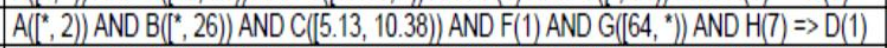 & 1 & 1 & 1.0 & 0.011111 & 0.014085 \\
\hline 26 & $\mathrm{~A}\left(\left[\left[^{*}, 2\right)\right)\right.$ AND B((26,31)) AND C( $\left.\left({ }^{*}, 5.13\right)\right)$ AND $F(1)$ AND G( $\left.\left({ }^{*}, 64\right)\right)$ AND $H(5) \Rightarrow D(1)$ & 1 & 1 & 1.0 & 0.011111 & 0.014085 \\
\hline 27 & $\mathrm{~A}\left(\left(2,{ }^{*}\right)\right)$ AND B( $\left.\left({ }^{*}, 26\right)\right)$ AND C( $\left.\left({ }^{*}, 5.13\right)\right)$ AND F(3) AND G( $\left.\left({ }^{*}, 64\right)\right)$ AND H(45) $\Rightarrow \mathrm{D}(1)$ & 1 & 1 & 1.0 & 0.011111 & 0.014085 \\
\hline 28 & $\mathrm{~A}\left(\left[{ }^{*}, 2\right)\right) \operatorname{AND} B\left(\left({ }^{*}, 26\right)\right) \operatorname{AND} C\left(\left(10.38,{ }^{*}\right)\right)$ AND F(1) AND G( $\left.\left({ }^{*}, 64\right)\right)$ AND H(25) $\Rightarrow \mathrm{D}(0)$ & 1 & 1 & 1.0 & 0.011111 & 0.052632 \\
\hline 29 & 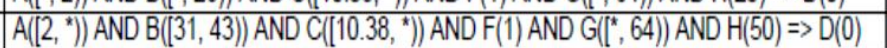 & 1 & $\mid 1$ & 1.0 & 0.011111 & 0.052632 \\
\hline 30 & $\mathrm{~A}\left(\left[2,{ }^{*}\right)\right)$ AND B $\left(\left[{ }^{*}, 26\right)\right)$ AND C((5.13, 10.38)) AND F(3) AND G([*, 64$\left.)\right)$ AND H(2) $\Rightarrow$ D(1) & 1 & 1 & 1.0 & 0.011111 & 0.014085 \\
\hline 31 & $\mathrm{~A}\left(\left[2,{ }^{*}\right)\right)$ AND B $([31,43))$ AND C( $\left(\left[{ }^{*}, 5.13\right)\right)$ AND F(3) AND G( $\left.\left({ }^{*}, 64\right)\right)$ AND H(50) $\Rightarrow$ D(1) & 1 & 1 & 1.0 & 0.011111 & 0.014085 \\
\hline 32 & $\mathrm{~A}\left(\left(2,{ }^{*}\right)\right)$ AND B $\left(\left(43,{ }^{*}\right)\right)$ AND $C((5.13,10.38))$ AND F(1) AND G( $\left.\left({ }^{*}, 64\right)\right)$ AND H(25) $\Rightarrow$ D $(1)$ & 1 & 1 & 1.0 & 0.011111 & 0.014085 \\
\hline 33 & $\mathrm{~A}\left(\left(2,{ }^{*}\right)\right) \mathrm{AND} B((31,43))$ AND C((5.13, 10.38)) AND F(1) AND G([64, $\left.\left.{ }^{*}\right)\right)$ AND H(8) $\Rightarrow \mathrm{D}(1$ & 1 & 1 & 1.0 & 0.011111 & 0.014085 \\
\hline 34 & $\left.\mathrm{~A}\left({ }^{*}, 2\right)\right) \mathrm{AND} \mathrm{B}((31,43)) \mathrm{AND} C\left(\left[{ }^{*}, 5.13\right)\right)$ AND F(3) AND $\mathrm{G}\left(\left[64,{ }^{*}\right)\right)$ AND $\mathrm{H}(7) \Rightarrow \mathrm{D}(0)$ & 1 & 1 & 1.0 & 0.011111 & 0.052632 \\
\hline
\end{tabular}

\section{REFERENCES}

[1] Bania, R.K. and Halder, A., 2020. R-Ensembler: A greedy rough set based ensemble attribute selection algorithm with $\mathrm{kNN}$ imputation for classification of medical data. Computer Methods and Programs in Biomedicine, 184, p.105122.

[2] Jones, D.E., Ghandehari, H. and Facelli, J.C., 2016. A review of the applications of data mining and machine learning for the prediction of biomedical properties of nanoparticles. Computer methods and programs in biomedicine, 132, pp.93-103.

[3] Kononenko, I., 2001. Machine learning for medical diagnosis: history, state of the art and perspective. Artificial Intelligence in medicine, 23(1), pp.89-109.

[4] Memarian, N., Kim, S., Dewar, S., Engel Jr, J. and Staba, R.J., 2015. Multimodal data and machine learning for surgery outcome prediction in complicated cases of mesial temporal lobe epilepsy. Computers in biology and medicine, 64, pp.67-78.
[5] Dash, M. and Liu, H., 1997. Feature selection for classification. Intelligent data analysis, 1(3), pp.131156.

[6] C. Ding , H. Peng , Minimum redundancy feature selection from microarray gene expression data, in: Proceedings of IEEE Computational Systems Bioinformat- ics, 2003, pp. 523-528.

[7] M. Sebban , R. Nock , A hybrid filter/wrapper approach of feature selection using information theory, J. Inform. Math. Sci. 35 (2002) 835-846.

[8] H. Liu , L. Yu , Toward integrating feature selection algorithms for classification and clustering, IEEE Trans. Knowl. Data Eng. 17 (6) (2005) 494-502.

[9] Zhong, N., 2001. A rough sets based knowledge discovery process. International Journal of Applied Mathematics and Computer Science, 11(3), pp.101117.

[10] Pawlak, Z., 1984, December. On learning — a rough set approach. In Symposium on Computation Theory (pp. 
International Journal of Engineering Research and Technology. ISSN 0974-3154 Vol.13, No.3 (2020), pp. 552-559

(C) International Research Publication House. https://dx.doi.org/10.37624/IJERT/13.3.2020.552-559

197-227). Springer, Berlin, Heidelberg.

[11] Nabwey, Hossam A. "A Hybrid Approach for Extracting Classification Rules Based on Rough Set Methodology and Fuzzy Inference System and Its Application in Groundwater Quality Assessment." In Advances in Fuzzy Logic and Technology 2017, pp. 611-625. Springer, Cham, 2017.

[12] Nabwey, Hossam A., M. Modather, and M. Abdou. "Rough set theory based method for building knowledge for the rate of heat transfer on free convection over a vertical flat plate embedded in a porous medium." In 2015 International Conference on Computing, Communication and Security (ICCCS), pp. 1-8. IEEE, 2015.

[13] Nabwey, H.A.. An approach based on Rough Sets Theory and Grey System for Implementation of RuleBased Control for Sustainability of Rotary Clinker Kiln. International Journal of Engineering Research and Technology, Volume 12, Number 12 (2019), pp. 2604-2610

[14] Shaaban, Shaaban M., and H. Nabwey. "A decision tree approach for steam turbine-generator fault diagnosis." International Journal of Advanced Science and Technology 51 (2013): 59-66.

[15] Shaaban, Shaaban M., and Hossam A. Nabwey. "A probabilistic rough set approach for water reservoirs site location decision making." In International Conference on Computational Science and Its Applications, pp. 358-372. Springer, Berlin, Heidelberg, 2012.

[16] Shaaban, Shaaban M., and Hossam A. Nabwey. "Rehabilitation and reconstruction of asphalts pavement decision making based on rough set theory." In International Conference on Computational Science and Its Applications, pp. 316-330. Springer, Berlin, Heidelberg, 2012.

[17] Shaaban, M., and A. Nabwey. "Transformer fault diagnosis method based on rough set and generalized distribution table." Int J IntellEngSyst 5 (2012): 17-24.

[18] Mohamed, HossamAbdElmaksoud. "An Algorithm for Mining Decision Rules Based on Decision Network and Rough Set Theory." In International Conference on Ubiquitous Computing and Multimedia Applications, pp. 44-54. Springer, Berlin, Heidelberg, 2011.

[19] Zhao, Hong, Ping Wang, Qinghua Hu, and Pengfei Zhu. "Fuzzy Rough Set Based Feature Selection for Large-Scale Hierarchical Classification." IEEE Transactions on Fuzzy Systems 27, no. 10 (2019): 1891-1903.

[20] Nabwey, Hossam A., and Mahdy S. El-Paoumy. "An integrated methodology of rough set theory and grey system for extracting decision rules." International Journal of Hybrid Information Technology 6, no. 1 (2013): 57-65.
[21] Pathak, H.K., George, R., Nabwey, H.A., El-Paoumy, M.S. and Reshma, K.P., 2015. Some generalized fixed point results in ab-metric space and application to matrix equations. Fixed Point Theory and Applications, 2015(1), pp.1-17.

[22] George, R., Nabwey, H.A., Reshma, K.P. and Rajagopalan, R., 2015. Generalized cone b-metric spaces and contraction principles. Mat. Vesn, 67(4), pp.246-257.

[23] Nabwey, H.A., Boumazgour, M. and Rashad, A.M., 2017. Group method analysis of mixed convection stagnation-point flow of non-Newtonian nanofluid over a vertical stretching surface. Indian Journal of Physics, 91(7), pp.731-742.

[24] Somu, N., MR, G.R., Kalpana, V., Kirthivasan, K. and VS, S.S., 2018. An improved robust heteroscedastic probabilistic neural network based trust prediction approach for cloud service selection. Neural Networks, 108, pp.339-354.

[25] Nivethitha, S., Raman, M.G., Gireesha, O., Kannan, K. and Sriram, V.S., 2019. An improved rough set approach for optimal trust measure parameter selection in cloud environments. Soft Computing, 23(22), pp.11979-11999.

[26] Raman, M.G., Nivethitha, S., Kannan, K. and Sriram, V.S., 2019. A hybrid approach using rough set theory and hypergraph for feature selection on highdimensional medical datasets. Soft Computing, 23(23), pp.12655-12672.

[27] Berge, C., Graphs and hypergraphs. American Elsevier Publishing Co., Inc., New York/North Holland Publishing Co., Amsterdam- London, 1973.

[28] Kannan, K., Kanna, B.R. and Aravindan, C., 2010. Root mean square filter for noisy images based on hyper graph model. Image and Vision Computing, 28(9), pp.1329-1338.

[29] Dharmarajan, R. and Kannan, K., 2012. On minimal transversals in simple hypergraphs. International Journal of Computational and Applied Mathematics, 7(2), pp.117-123.

[30] Khozeimeh, F., Alizadehsani, R., Roshanzamir, M., Khosravi, A., Layegh, P. and Nahavandi, S., 2017. An expert system for selecting wart treatment method. Computers in biology and medicine, 81, pp.167-175.

[31] Khozeimeh, F., Jabbari Azad, F., Mahboubi Oskouei, Y., Jafari, M., Tehranian, S., Alizadehsani, R. and Layegh, P., 2017. Intralesional immunotherapy compared to cryotherapy in the treatment of warts. International journal of dermatology, 56(4), pp. $474-478$ 